
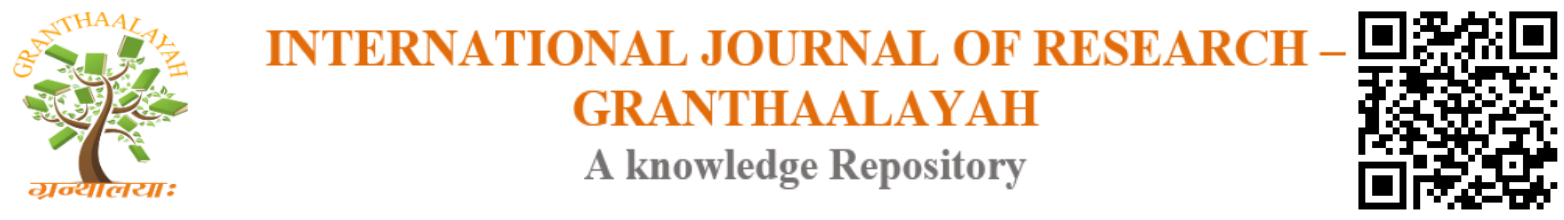

Social

\title{
TRENDS IN INCIDENCE OF POVERTY AMONG SCHEDULED CASTES: THE CASE OF KARNATAKA
}

\author{
Sumayya $\operatorname{Naz}^{1}$, Vishwanatha ${ }^{2}$ \\ ${ }^{1}$ Research Scholar, Department of Economics, Mangalore University, India \\ ${ }^{2}$ Professor of Economics, Department of Economics, Mangalore University, India
}

\begin{abstract}
Historically, the Scheduled Castes (SCs) in India have been the victims of social exclusion and marginalization along with living under poverty. The SCs in Karnataka form a sizeble part with 17 per cent of the State's population and more than 75 per cent of them living in rural areas. They have continued to be socially, educationally and economically backward even today. Due to various constitutional provisions and welfare programmes for SCs, the incidence of poverty is declining in percentage terms but a large number of SC population still continue to be poor. A large number of studies have focused on the issue of poverty in general, but not many studies relating to incidence of poverty across social groups in India and Karnataka. In this backdrop, the present paper is to analyse the trends in prevalence of poverty among SCs in Karnataka at macto perspective.
\end{abstract}

Keywords: Scheduled Caste; Poverty; Marginalised Groups; Dalits; Karnataka.

Cite This Article: Sumayya Naz, and Vishwanatha. (2019). "TRENDS IN INCIDENCE OF POVERTY AMONG SCHEDULED CASTES: THE CASE OF KARNATAKA.” International Journal of Research - Granthaalayah, 7(6), 143-150. 10.29121/granthaalayah.v7.i6.2019.781.

\section{Introduction}

The Scheduled Castes (SCs) in Karnataka form a sizeble part with 17 per cent of the State's population and more than 75 per cent of them living in rural areas. As per census reports, the SC population in the State has increased from 85.64 lakh in 2001 to 104.75 lakh in 2011, registering a decennial growth rate of 22.32 per cent. The SC population constitutes 17.15 per cent of the total population of the State. The highest proportion of SC population is returned from Kolar District with 30.32 per cent, followed by Chamarajanagar District with 25.42 per cent. The least proportion of Scheduled Caste population is recorded in the coastal district of Udupi (6.41 per cent) and preceded by Dakshina Kannada (7.09 per cent) District. The SCs are known by different names in different parts of the state and comprise many sub-castes and communities. Presently, there are 101 sub castes among SCs, Adi Karnataka, Madiga, Banjara, Bhovi, Holeya, Adi Dravida and Bhambi together constitute 85.0 per cent of the SC population of the state. Adi Karnataka is numerically the largest SC with a population of 2,199,170, constituting 25.7 per cent of the state's 
SC population. They are followed by Madiga (15.2 per cent), Banjara (11.6 per cent), Bhovi (11.2 per cent), Holeya (7.5 per cent), Adi Dravida (7.2 per cent) and Bhambi (6.6 per cent).

The SC community is marginalized social group in Karnataka. They have continued to be socially, educationally and economically backward even today. Due to various constitutional provisions and welfare programmes for SCs, the incidence of poverty is declining in percentage terms but a large number of SC population still continue to be poor. Poverty is concentrated among socially disadvantaged sections of the populations such as SCs and Scheduled Tribes (Thorat and Mahamalik, 2007; De Haan and Dubey, 2005; Newman and Thorat, 2009 and GoI 2012). Karnataka is no exception to this general trend. The incidence of poverty among SCs in Karnataka was 33.2 per cent in 2011-12 while it was 21.2 per cent for overall. Against the above backdrop, the present paper is to analyse the trends in prevalence of poverty among SCs in Karnataka at macto perspective with the following g objectives.

\section{Aim of the Paper and Data Sources}

The main objectives of the study are;

1) to understand the concept and measurement of poverty in the Indian context.

2) to analyse the trends in prevalence of poverty among SCs in Karnataka at macro perspective.

The paper is prepared exclusively based on the secondary sources of information. The major information sources are obtained from Census documents, Planning Commission and NSSO reports, articles, etc.

\section{Concept of Poverty, Measurement of Poverty and Identification of Poor}

The concept of poverty is complex dynamic and multi-dimensional. It varies across the time, space and social stratification. Commanly, the term poverty is defined as the inability of a certain section of the society to obtain minimum income to meet the basic needs of life such as food, cloth, shelter, health care and education. Identification of the poor, measurement, and estimating the magnitude of poverty have received considerable attention among academicians and policy makers across the world. Identification of the poor is important for Central and State Governments to implement various welfare programmes and schemes. Before the identification of the poor, the question is how to measure the poverty of an individual or family and what are the indicators to be considered to assess poverty. The debate is still on regarding the concept of poverty and its measurement. According to Sen, poverty is a complex phenomenon that requires a clear analysis from various dimensions. Amartya Sen (1997) has characterised poverty as a "capability deprivation", where a person lacks the 'subsistence freedoms' to lead the kind of life. The concept of poverty must be understood with reference to the circumstances and the level of progress of a country. It varies across regions and has different faces, shapes, and magnitudes. Poverty is generally defined (from various sources) as the inability to secure a minimal level of living. In other words, the person or household who fails to obtain minimum income to meet the basic needs of life such as food, cloth, shelter, healthcare, and education. 
The World Bank in its studies, defines poverty as "the inability to attain a minimum standard of living". Martin Ravallion of the World Bank in various reports defines poverty using the 'dollar a day' benchmark. Amartya Sen suggests that needs-fulfilment is the more useful measure than use of any kind of money-metric measure of poverty. Sen in his book 'The Idea of Justice' argues that income approach is the wrong tool to measure poverty as it considers people earning less than a certain amount annually as poor, which is not an accurate measure of how well people live (Sen, 2009).

The Planning Commission traditionally uses the 'basic nutritional intake of calories' as an indicator of poverty, based on the recommendation of the Expert Group on Estimation of Proportion and Number of Poor (chaired by D. T. Lakdawala). And it was applied to the NSS consumer expenditure survey data since 1973-74 (Planning Commission, 1993). Accordingly, poverty is defined by the government in terms of food intake: people who cannot consume 2,400 calories of energy a day in rural areas or 2,100 calories in urban areas are deemed poor, or below the poverty line (BPL) by taking into the account the minimum level of per capita consumption expenditure. The calories intake is converted into monetary terms and the poverty line is defined as a minimum level of income or expenditure, which is periodically updated. Dandekar and Rath (1971) adopted a benchmark by considering the per capita monthly consumer expenditure of about $₹ 15$ in rural areas and ₹22.5 in urban areas at 1960-01 prices to measure and analyse the poverty level in India. The latest updated poverty line fixed by the Government of India for 2011-12 based on the recommendations of the Tendulkar Committee using Household Consumer Expenditure Survey 2011-12 data of the National Sample Survey (NSS) 68th round. Accordingly, with the poverty line at all India level at monthly per capita expenditure (MPCE) of Rs. 816 for rural areas and Rs. 1000 for urban areas in 2011-12. (Planning Commission, 2014). Based on these criteria, the Planning Commission has been estimating the incidence of poverty at the national and state level by using the large sample survey of consumer expenditure data of the National Sample Survey (NSS). The incidence of poverty has been measured by the percentage of people living below the poverty line (known as the poverty or headcount ratio).

\section{Trends in Incidence of Poverty}

A large proportion of India's population live in abject poverty and this is confirmed from various sources. The data on the extent of poverty in India remains much debated and is very complicated. The Planning Commission in 2004-05 has estimated that 28.5 per cent of the country's population was poor. Table-1 presents evidence on the existing poverty level in the country and Karnataka across rural and urban areas. The Planning Commission estimated the poverty line for 2004-05 based on a National Sample Survey Organisation (NSSO) data, which said an income of ₹539 per month for urban families was enough to purchase 2,100 calories of nutrition and an income of ₹ 356 per month was enough to purchase 2,400 calories of nutrition in rural areas. However, different government bodies disputed the plan panel's estimate. In 2007, Arjun Sengupta's Committee said that 77 per cent of India's population was living below the poverty line, earning less than ₹ 20 per day. The World Bank's own estimate of poverty in 2007 has been drastically revised by the new cost-of-living data. Accordingly, the poverty level in India was 41.6 per cent based on \$ 1.25 line in 2005 purchasing power parity (PPP). The ADB has estimated an even higher benchmark of $\$ 1.35$ per person per day and if these criteria is applied to India, nearly 55 per cent of our population is to be considered as poor (ADB, 2008). 
Table 1: Trends in Poverty Ratios in Karnataka and India (\%)

\begin{tabular}{|l|l|l|l|l|l|l|}
\hline \multirow{2}{*}{ Year } & \multicolumn{3}{|c|}{ Karnataka } & \multicolumn{3}{c|}{ All-India } \\
\cline { 2 - 7 } & Rural & Urban & Combined & Rural & Urban & Combined \\
\hline $1973-74$ & 55.14 & 52.53 & 54.47 & 56.44 & 49.01 & 54.88 \\
\hline $1977-78$ & 48.18 & 50.36 & 48.78 & 53.07 & 45.24 & 51.32 \\
\hline $1983-84$ & 36.33 & 42.82 & 38.24 & 45.85 & 40.79 & 44.48 \\
\hline $1987-88$ & 32.82 & 48.42 & 37.53 & 39.09 & 38.20 & 38.86 \\
\hline $1993-94$ & 29.88 & 40.14 & 33.16 & 37.27 & 32.36 & 35.97 \\
\hline $1999-00$ & 17.38 & 25.25 & 20.04 & 27.09 & 23.62 & 26.10 \\
\hline $2004-05$ & 20.80 & 32.60 & 25.00 & 28.3 & 25.7 & 27.5 \\
& $(37.5)$ & $(25.9)$ & $(33.4)$ & $(41.8)$ & $(25.7)$ & $(37.2)$ \\
\hline $2009-10 *$ & 26.10 & 19.60 & 23.6 & 33.80 & 20.90 & 29.80 \\
\hline
\end{tabular}

* Data on poverty estimates as per the Tendulkar Committee's recommendations and data in the brackets is also from the same.

Source: Planning Commission (2012), Press Note on Poverty Estimates, 2009-10, Government of India, March 2012.

The Incidence of poverty has become a major concern in India and also in Karnataka. Karnataka is the poorest among the southern States (Tamil Nadu, Andhra Pradesh, and Kerala) according to the data on poverty recently released by an Expert Committee set up by the Planning Commission. The committee has estimated that a little over one-third of Karnataka's population lived below the poverty line in 2004-05. The committee has revised rural poverty levels in India in 2004-05, from 28.3 per cent to 41.8 per cent, a significant upward revision. The committee established the poverty line for 2004-05 at ₹ 417.8 per capita a month for rural Karnataka and at ₹ 588.10 for urban areas of the State. The poverty line implies a minimum consumption expenditure level required by a person to procure a standardised basket of goods and services to satisfy basic needs. The report reveals that the head-count ratio of people below the poverty line in Karnataka is far higher than in Andhra Pradesh, Tamil Nadu, and Kerala. In fact, at 33.9 per cent, the poverty ratio is only marginally lower than the national average of 37.2 per cent in 2004-05. As per revised estimation of Tednulkar Committee for the year 2011-12, the rural poverty level is 24.5 per cent and urban poverty is 15.3 per cent in Karnataka (Table 2). Data clerly shows that both rural and urban poverty has contentiously declined in Karnataka \& India during the period 2004-05 to 2011-12.

Table 2: Percentage of population below Poverty levels in India and Karnataka (Tendulkar Methodology)

\begin{tabular}{|l|l|l|l|l|l|l|}
\hline \multirow{2}{*}{ Year } & \multicolumn{3}{|c|}{ Karnataka } & \multicolumn{3}{c|}{ India } \\
\cline { 2 - 7 } & \multicolumn{1}{|c|}{ Rural } & Urban & Overall & Rural & Urban & Overall \\
\hline $2004-05$ & 37.5 & 25.9 & 33.9 & 41.8 & 25.7 & 37.2 \\
\hline $2009-10$ & 26.1 & 19.6 & 23.6 & 33.8 & 20.9 & 29.8 \\
\hline $2011-12$ & 24.5 & 15.3 & 21.2 & 25.7 & 13.7 & 21.9 \\
\hline
\end{tabular}

Source: Planning Commission (2014).

\section{Trends in Poverty level among SCs in Karnataka as per Tendulkar estimation}

The Planning Commission has updated the poverty lines and poverty ratios based on the recommendations of the Tendulkar Committee report by using Household Consumer Expenditure 
Survey data of the National Sample Survey reports. Suresh Tendulkar modifications were made considering other basic requirements of the poor, such as housing, clothing, education, health, sanitation, conveyance, fuel etc. thus making the poverty line more realistic. Figure- 1 provides the data on trends of poverty (rural \& urban combined) in Karnataka during 1993-94 to 2011-12. The poverty rate among SC and ST, which constitutes about 17.1 and 5.3 per cent of the total population respectively, is 33.2 and 31.5 per cent respectively in 2011-12.

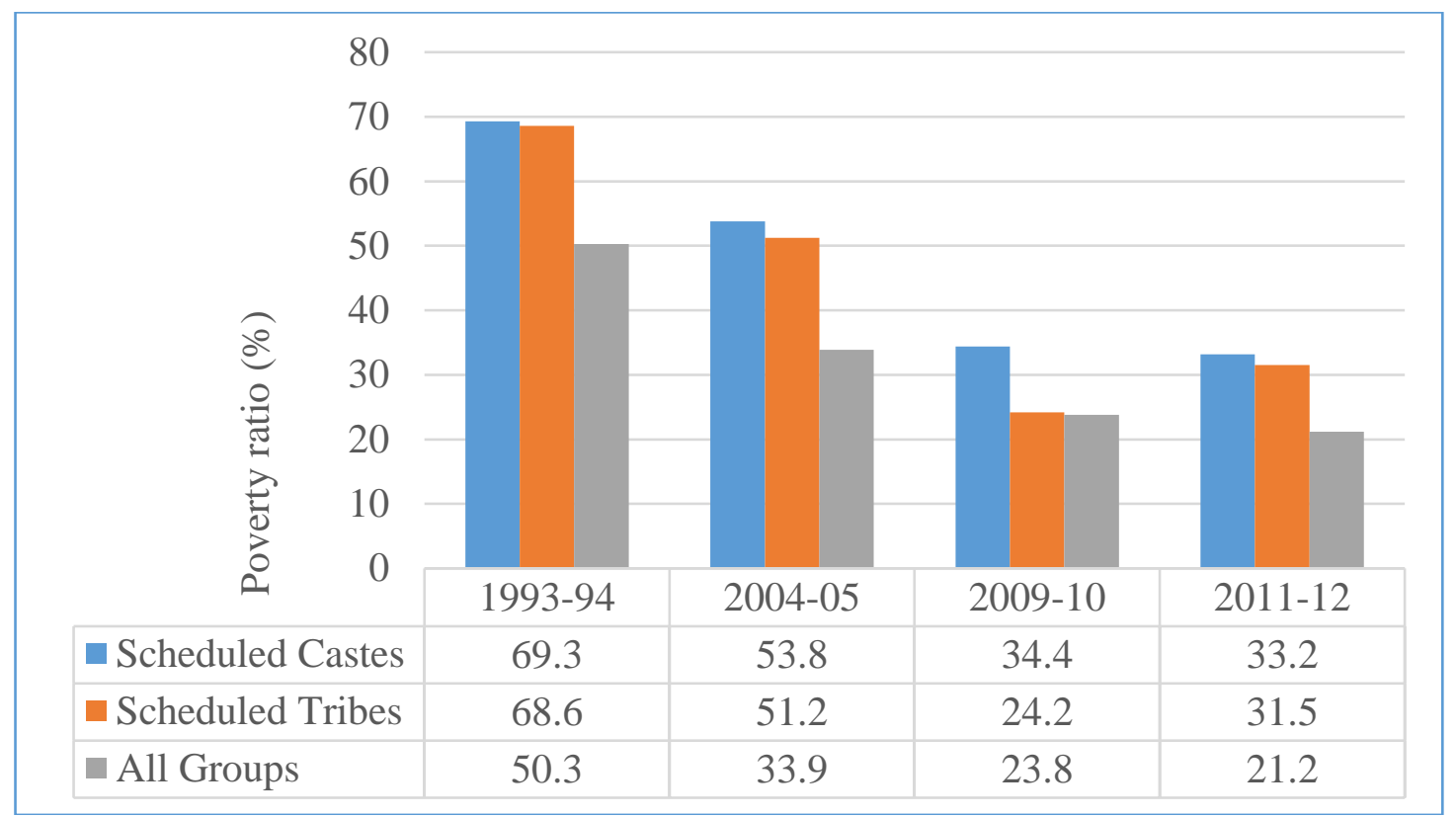

Figure 1: Poverty level in Karnataka State by social groups as per Tendulkar estimation (1993-94 to 2011-12)

Source: (a). Planning Commission (2014). (b). Panagaria, A and Megha Mukim (2014).

Incidence of poverty level across socio-religious groups in Karnataka is shown in the Table-3.

In 2011-12, the poverty is 21.2 per cent with substantially high incidence in rural areas (24.5 per cent) as compared to the urban areas (15.3 per cent). In the state, three groups namely SCs, STs and Muslims have substantially high incidence of poverty as compared to that of Hindu High Caste (HHC) and Hindu Other Backward Castes (HOBC). This is also true in the case of both rural and urban areas. The poverty among SCs, STs and Muslims accounts for 33.2 per cent, 31.5 per cent and 26.5 per cent, respectively. The proportion of poor among HOBC and HHC is relatively low, particularly in urban areas. It is 17.8 per cent among $\mathrm{HOBC}$ and 13.7 per cent among $\mathrm{HHC}$ in the state. The poverty in rural areas is 20 per cent and 19 per cent respectively and 11.6 and 7 per cent respectively in urban areas. It indicates that poverty has remained a chronic condition for almost 33 per cent of SCs in the state and it is highest among rural SCs (37.1 per cent). The incidence of poverty is not only higher but also chronic among them, despite the implementation of various poverty alleviation programmes. The incidence of poverty is declining among all social groups in India. The incidence of poverty declining significantly among all the social groups, but SCs/STs, they continued to experience a greater incidence of poverty, as compared to others. 
Table 3: Incidence of Poverty among social and religious groups in Karnataka (Tendulkar Methodology)

\begin{tabular}{|l|l|l|l|}
\hline \multirow{2}{*}{ Social / religious groups } & \multicolumn{3}{c|}{ Karnataka (\%) } \\
\cline { 2 - 4 } & Rural & Urban & Total \\
\hline Scheduled Castes (SCs) & 37.1 & 25.0 & 33.2 \\
\hline Scheduled Tribes (STs) & 30.8 & 33.7 & 31.5 \\
\hline Hindu Other Backward Castes (HOBC) & 20.2 & 11.6 & 17.8 \\
\hline Hindu High Caste (HHC) & 19.2 & 7.1 & 13.7 \\
\hline Muslims & 30 & 23.8 & 26.5 \\
\hline Total & 24.5 & 15.3 & 21.2 \\
\hline
\end{tabular}

Source: Estimated by Nayak et al (2016) based on Consumption Expenditure data of NSSO, 201112.

The incidence of poverty by household type across social and religious groups is presented in the Table-4. It has been observed tht the lowest poverty is among HHC households among all the household types. In most of the household type, the highest poverty is encountered by SC, STs and Muslims. The casual labour household have the highest poverty ratio (35.7 per cent) which is more than four time higher than that of regular salaried households (8.1 per cent) and more than double of that self-employed households (19.9 per cent). Among casual labour households, the highest poverty is among STs (50.6 per cent) followed by SCs and Muslims (more than 37 per cent for both). Among self-employed households, the highest poverty is encountered by the SC households (37.4 per cent) followed by Muslims (25.3 per cent) and STs (19.5 per cent, and among regular salaried, the poverty is almost double among SCs (15.7 per cent) that the average level (8.1 per cent).

Table 4: Incidence of Poverty by type of households among social and religious groups in

Karnataka

\begin{tabular}{|l|l|l|l|l|l|l|}
\hline SI No & $\begin{array}{c}\text { Social / religious } \\
\text { groups }\end{array}$ & $\begin{array}{c}\text { Self-employed } \\
(\mathbf{S E})\end{array}$ & $\begin{array}{c}\text { Regular Salaried } \\
(\mathbf{R S})\end{array}$ & $\begin{array}{c}\text { Casual Labourer } \\
(\mathbf{C L})\end{array}$ & Others & Total \\
\hline 1 & ST & 19.5 & 11.9 & 50.6 & 13.8 & 31.6 \\
\hline 2 & SC & 37.4 & 15.7 & 37.8 & 25.1 & 32.9 \\
\hline 3 & HOBC & 17.7 & 3.9 & 31.2 & 18.5 & 17.6 \\
\hline 4 & HHC & 14.8 & 6.2 & 29.4 & 4.9 & 13.4 \\
\hline 5 & Muslim & 25.3 & 18.4 & 37.5 & 9.3 & 26.4 \\
\hline & Total & 19.9 & 8.1 & 35.7 & 13.4 & 20.9 \\
\hline
\end{tabular}

Source: Estimated by Nayak et al (2016) based on Consumption Expenditure data of NSSO, 2011 12.

Note:

1) Self-employed (SE)- Self-employed in agriculture and non-agriculture in rural areas and self-employed in urban areas.

2) Regular Salaried (RS)- Regular Salaried in both rural and urban areas,

3) Casual labours (CL)- Casual labours in agriculture and non-agriculture in rural areas and casual labour urban areas; and Others include households which does not have any income economic activities. 


\section{Conclusions}

Estimates of poverty among social groups clearly show that though the incidence of poverty declined significantly among SCs and they continued to experience a greater incidence of poverty, as compared to others. There have been few studies conducted on poverty of SCs in Karnataka. A large sample survey conducted by Vishwanatha (2013) in Karnataka observed that 93 per cent of total surveyed SC households in the state still living under poverty line and major source of income to SC families is labour wage, mainly agriculture labour. Vishwanatha (2009) expressed that the reason for high incidence of poverty among Dalits is due to lack of asset ownership and productive resources. Maruti's study in Karnataka, based on the census data shows that SC populations are concentrated as agricultural labourers and this trend continues over decades across census periods (Maruti, 2006). Ramakrishnappa and Vishwanatha (2015) in their study based on secondary analysis found that the SCs confronted with multiple deprivations such as high level of poverty and unemployment, landlessness, and lack of institutional credit support. A micro level study by Biradar (2008) in sample villages of two districts in Karnataka reveals that the incidence of poverty was found to be higher in the case of SCs/STs as compared to others. The study concludes that lack of productive assets (land), limited occupational diversification, higher illness prevalence rate, higher incidence of child labour, labour market discrimination (in terms of low rates in the rural non-farm occupations), and limited access to social security schemes attributed to a greater incidence of poverty among SC/STs as compared to Others.

As per Agricultural Census (2012) of Karnataka, the average size of operational holdings by SCs is less at 1.18 hectares, while for others it was 1.68 heactares. Most of the people from SC category are either landless or hold marginal and small land in rural areas which is not enough to survive their livelihoods and live in poverty. The implementation of on-going poverty alleviation programme should be streamlined to ensure equitable reach out to SC community. There is need to initiate special time-bound programmes by Government of Karnataka for landless rural SCs by distributing productive land to them in order to tackle the the poverty. A large number of SCs were found to be living under poverty syndrome and hence, government should encourage SC population and facilitate to start their own non-farm enterprises.

\section{References}

[1] Biradar, R. R (2008). "Incidence of Poverty among social groups in Rural India: Why do SCs/STs experience greater incidence of Poverty", SRTT Project Report, ISEC, Bangalore.

[2] Dandekar, V. M. and N. Rath (1971). Poverty in India, Indian School of Political Economy, Pune.

[3] De Haan Arjun and Dubey, A (2005). "Poverty, Disparities, or the Development of Underdevelopment in Orissa", Economic and Political Weekly, May 28-June 4, pp. 2321-2329.

[4] Government of Karnataka (2012). Report of the Operational Holdings in Karnataka: Agricultural Census 2010-11, DES, Bangalore.

[5] Maruti, I (2006). 'Changes in Work participation of Weaker Sections in Karnataka: A study of last three Decade', ADRT Research Report, Institute for Social and Economic Change, Bangalore.

[6] Nayak et al (2016). "Poverty in Karnataka: Caste and Regional Dimensions", Workiking Paper Series, Vol. 10, Issues. 1, IIDS, New Delhi.

[7] Panagaria, Arvind and Megha Mukim (2014). "A Comprehensive Analysis of Poverty in India", Asian Development Review, Vol. 31, No. 1, pp. 1-52.

[8] Planning Commission (1993). Report of the Expert Group on Estimation of Proportion and Number of Poor, Perspective Planning Division, Government of India, New Delhi. 
[9] Planning Commission (2009). 'Report of the Expert Group to Review the Methodology for Estimation of Poverty (under the chairmanship of Prof. Suresh D Tendulkar)', November 2009, Government of India, New Delhi.

[10] Planning Commission (2012). Press Note on Poverty Estimates, 2009-10, March 2012, Government of India, New Delhi.

[11] Planning Commission (2014). Report of the Expert group to review the Methodology for Measurement of Poverty, June 2014, Government of India.

[12] Ramakrishanappa, V and Vishwanatha (2015). "Nature and Extent of Economic Deprivation among Dalits in Rural India: An Analysis", IJSR-International Journal of Scientific Research, Vol. 4, Issue 2, February 2015, pp. 1-2.

[13] Sen, Amartya (1997). Inequality Reexamined. Cambridge: MSS, Harvard University press.

[14] Sen, Amratya (2009): The Idea of Justice, Penguin, UK.

[15] Thorat and Newman (2007). "Caste and Economic Discrimination: Causes, Consequences and Remedies", Economic and Political Weekly, 42(41).

[16] Thorat, Sukhadeo and Motilal Mahamalik (2007). Chronic Poverty and Socially Disadvantaged Groups: Analysis of Causes and Remedies. CPRC-IIPA Working Paper 33. Indian Institute of Public Administration and Chronic Poverty Research Centre.

[17] Vishwanatha (2009). 'Globalization, Livelihoods and Social Exclusion of Dalits in India', In: Vishwanatha and L C Mallaih (eds.) Globalization and Dalits: Magnitude and Impact, New Delhi: Abhijeet Publications, pp.1-36.

[18] Vishwanatha (2013). "Discrimination and Social Exclusion: A Study on the Development Experience of Dalits in Karnataka”, ICSSR sponsored Research Project, CSEIP Centre, Mangalore University.

[19] World Bank (2010). "New Global Poverty Estimates-What it means for India", www.worldbank.org.in (Available at: http://go.worldbank.org)

*Corresponding author.

E-mail address: norrie_junegayeta@ yahoo.com.ph 